\title{
Growth pattern and final height of very preterm vs. very low birth weight infants
}

\author{
Jonneke J. Hollanders ${ }^{1}$, Sylvia M. van der Pal ${ }^{2}$, Paula van Dommelen ${ }^{2}$, Joost Rotteveel ${ }^{1}$, Martijn J.J. Finken ${ }^{1}$ and
} on behalf of the Dutch POPS-19 Collaborative Study Group ${ }^{16}$

BACKGROUND: Both very preterm (VP; i.e., gestational age $<32$ weeks) and very low birth weight (VLBW; i.e., birth weight $<1,500 \mathrm{~g}$ ) are used as inclusion criteria by studies on preterm birth. We aimed to quantify the impact of these entities on postnatal growth until final height.

METHODS: Subjects born VP and/or with VLBW from the Project On Preterm and Small-for-gestational-age infants cohort were classified as follows: (1) VP+NLBW+ $(n=495)$, (2) VP+NLBW - $(n=207)$, or (3) VP - NLBW+ $(n=296)$ infants. Anthropometric data were collected at birth, 3, 6, 12, and 24 months' corrected age, and at 5 and 19 years. At 19 years, $590 / 998$ (59\%) of the subjects enrolled in 1983 were followed up.

RESULTS: Birth size was smallest in the VP - NLBW+ group compared with the VP+NLBW+ and VP+NLBW - groups. During childhood, length, weight, and head circumference SD scores increased in the VP-NLBW+ group, whereas SD scores in the VP+NLBW+ and VP+NLBW - groups either remained stable or decreased. Despite catch-up growth, VP - / VLBW+ infants remained the shortest and lightest at age 19. CONCLUSION: Classification on the basis of VP and VLBW impacts growth, causing different growth patterns for infants born $V P+N L B W+, V P+N L B W-$, or $V P-N L B W+$. For future studies, we recommend, at least for industrialized countries, including preterm infants based on gestational age.

I nfants born very preterm (i.e., VP $<32$ weeks of gestation) and/or with very low birth weight (i.e., VLBW $<1,500 \mathrm{~g}$ ) require admission to a Neonatal Intensive Care Unit (NICU). Early postnatal growth in such infants is often characterized by extrauterine growth retardation (EUGR) (1), caused by a combination of factors, including acute illnesses, glucocorticoid therapy, and feeding difficulties. Although the majority of these infants exhibit late postnatal catch-up growth, they often remain short and thin during childhood and adolescence (2). Moreover, postnatal growth in VP and/or VLBW infants has been associated with a variety of short- and longterm outcomes, such as cognitive functioning $(3,4)$, motor performance (4), and body composition (5).

However, most of the evidence on the long-term consequences of preterm birth on growth comes from studies in infants with VLBW (6-11), which can be attributed to prematurity, intrauterine growth retardation (IUGR), or both. Before the 1980s, prematurity was often based on birth weight in lieu of reliable ways to estimate gestational age. After the widespread application of ultrasound as a tool to accurately measure pregnancy duration (12), the majority of studies on preterm infants still used birth weight as an estimate of the degree of prematurity (6-11).

Although it is reasonable to assume that being born VP or with VLBW has different impacts on outcomes, surprisingly, this has been quantified only once before (13). In comparing VLBW with VP infants, VLBW was associated with an overrepresentation of small-for-gestational-age (SGA) births and with lower numbers experiencing neonatal morbidities. However, this study did not provide long-term follow-up and, therefore, it is not known whether the differences between these groups could be extended with growth after hospital discharge. Findings from studies in cohorts of infants born either VP or with VLBW that have provided follow-up until adulthood are incomparable because of the different standards of care at the time of birth $(5,7,8,14)$. The past 30 years were characterized by major changes including widespread use of antenatal glucocorticoid therapy, introduction of synthetic surfactant, and more aggressive feeding policies. Such changes have resulted in improved chances for survival. Therefore, caution must be exercised in the comparison of populations born either VP or with VLBW from different birth eras. Consequently, the long-term impact of being born VP or with VLBW can only be studied within the same birth cohort.

Therefore, in this study, we aimed to quantify the impact of being born VP and/or with a VLBW on growth until adulthood. For this purpose, we used the data of the Dutch Project On Preterm and Small-for-gestational-age infants (POPS), which is,

\footnotetext{
${ }^{1}$ Department of Pediatrics, VU University Medical Center, Amsterdam, The Netherlands; ${ }^{2}$ Department of Child Health, TNO, Leiden, The Netherlands. Correspondence: Jonneke J. Hollanders (j.hollanders@vumc.nl)

${ }^{16}$ The members in the Dutch POPS-19 Collaborative Study Group are mentioned above References.

Received 18 July 2016; accepted 14 January 2017; advance online publication 31 May 2017. doi:10.1038/pr.2017.63
} 
to our knowledge, the only study to date that followed up children born both VP and/or with a VLBW into young adulthood.

\section{METHODS}

\section{Study Population}

The POPS cohort comprised $94 \%(n=1,334)$ of the infants born alive in the Netherlands in 1983 with a gestational age $<32$ weeks (VP) and/or with a birth weight $<1,500 \mathrm{~g}$ (VLBW). Gestational age was based on last menstrual period, pregnancy testing, and/or ultrasound. Subjects were excluded if they died during their hospital stay $(n=340)$. Thus, 998 subjects were included in this study. The inclusion criteria enabled us to compare groups of (1) VP+/ VLBW+ infants $(n=495),(2) \mathrm{VP}+/ \mathrm{VLBW}$ - infants $(n=207)$, and (3) VP - / VLBW+ infants $(n=296)$ (Figure 1). Approval of the medical ethical committees of all participating centers was obtained.

\section{Growth Assessment}

Subjects underwent growth assessment at birth, at 3, 6, 12, and 24 months of corrected age, and again at the chronological ages of 5 and 19 years, when all participants had reached final height. Followup was done by trained research nurses and/or physicians according to the standardized procedures. At ages 3 months- 2 years, anthropometric data were collected at outpatient clinics. At age 5, research staff made house visits, whereas at age 19 follow-up took place at 1 of the 10 involved research centers. Until the age of 2, length was measured in supine position to the nearest $1 \mathrm{~cm}$. From age 5 onward, standing height was measured to the nearest $1 \mathrm{~mm}$. Weight was measured to the nearest $5 \mathrm{~g}$ at birth, and during the follow-up visits to the nearest $0.1 \mathrm{~kg}$ on a balance scale. Head circumference (HC) was measured to the nearest $1 \mathrm{~cm}$ up to the age of 5 .

SD scores (SDSs) for length/height, weight, and HC were calculated $(15,16)$. Subjects with a birth weight and/or length of less than -2 SD were classified as SGA. Body mass index (BMI) was calculated as (weight $\left.(\mathrm{kg}) /(\text { length }(\mathrm{m}))^{2}\right)$ and converted to SDS (17).

\section{Statistical Analysis}

SDS for length/height, weight, BMI, and HC were compared between groups using a generalized estimating equation. The different measurement points were used as an interaction term with the different groups. A $P$ value of $\leqslant 0.05$ was considered as a significant difference, and $95 \%$ confidence intervals (95\% CIs) were calculated as described by Figueiras et al. (18).

\section{RESULTS}

Perinatal characteristics of participants were significantly different between the VP+/VLBW+, VP+/VLBW-, and $\mathrm{VP}-/ \mathrm{VLBW}+$ groups (Table 1). In general, the VP-I VLBW+ group showed significantly less neonatal morbidity and had a better Apgar score after $5 \mathrm{~min}$, whereas they were significantly more often SGA and born to mothers with (preexistent) hypertension and/or who smoked during pregnancy. The VP+/VLBW+ group had significantly more neonatal morbidity, a longer hospital stay, and more days on ventilation compared with the other two groups. The VP +/VLBW - group had the shortest hospital stay. However, ethnicity, marital status, and socio-economic status (SES) were not significantly different between the three groups, and target height SD and maternal height also did not differ between the three groups.

The response rate was different for the several follow-up visits (Figure 2). At age 19, 59\% of the infants included for

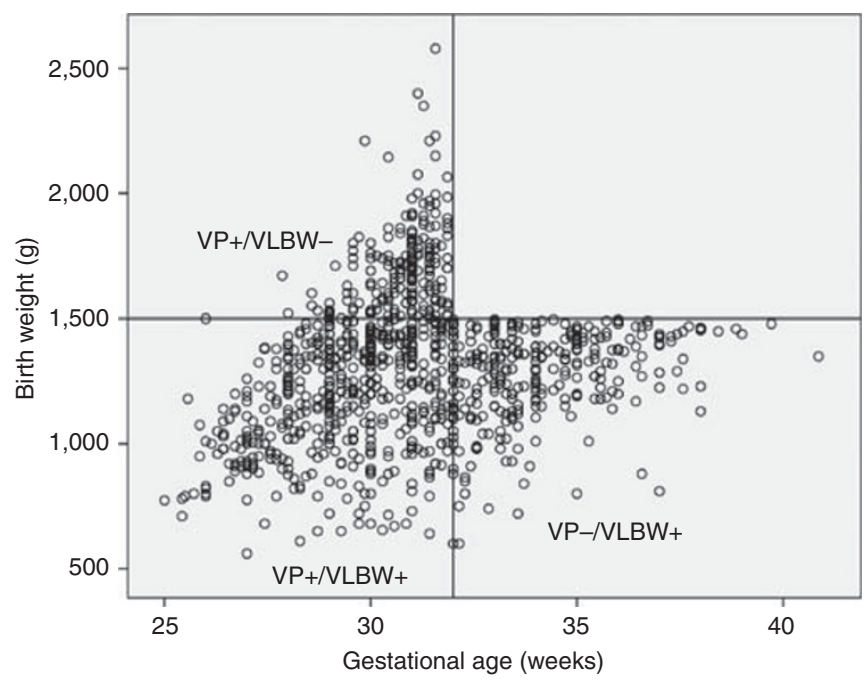

Figure 1. Distribution of our study population, with the three different groups (i.e., VP+/VLBW+, VP+/VLBW - and VP - NLBW+) indicated.

this study were followed up; for the other visits, the response rate was adequate. At age 19, responders were significantly different compared with the non-responders with regard to gender distribution, target height, pre-existent hypertension, ethnicity, and SES, whereas all other perinatal characteristics as well as the distribution of the subjects between the three groups did not differ (Table 2).

Length/height was significantly different between groups at all ages, except between the VP-/VLBW+ and VP+/VLBW+ groups at age 5 (Figure 3a). The VP+/VLBW - group was the tallest at all ages, whereas the $\mathrm{VP}-/ \mathrm{VLBW}+$ group remained the shortest.

Weight was significantly different between groups at all ages (Figure 3b), except for age 19 between the VP - /VLBW+ and the VP+/VLBW+ groups. Once again, the VP+/VLBW group consistently had the highest weight, whereas the VP - / VLBW+ group had the lowest.

$\mathrm{BMI}$ in the $\mathrm{VP}+/ \mathrm{VLBW}$ - group was significantly higher at all ages compared with the VP+/VLBW+ and VP - /VLBW+ groups, except for age 19 (Figure 3c). The BMI in the $\mathrm{VP}+/ \mathrm{VLBW}+$ and $\mathrm{VP}-/ \mathrm{VLBW}+$ groups was significantly different at ages 1,2 , and 5 .

HC was significantly different between groups at all ages (Figure 3d). The VP+/VLBW - group consistently had the largest HC, whereas the VP-/VLBW+ group had the smallest.

Table 3 shows the changes in SDS within the groups over time. Between birth and age 19, length/height SDS significantly increased in the VP-/VLBW+ group, while the VP+/VLBW+ and $\mathrm{VP}+/ \mathrm{VLBW}$ - groups showed a decrease in length/height SDS. A similar pattern was observed for weight SDS between birth and age 19. The greatest changes in SDS took place between birth and 3 months of corrected age, and between ages 5 and 19. BMI did not change in the VP+/VLBW - group between 3 months and age 19, but there was a significant increase in SDS in the VP+/VLBW+ and VP - /VLBW+ groups 
Table 1. Perinatal characteristics of the surviving subjects in the three groups

\begin{tabular}{|c|c|c|c|c|}
\hline & $\mathrm{VP}+/ \mathrm{VLBW}+n=495$ & $V P+/ V L B W-n=207$ & $\mathrm{VP}-/ \mathrm{VLBW}+n=296$ & Overall $P$ value \\
\hline Male & $250(50.5)$ & $134(64.7)$ & $139(47.0)$ & $<0.001^{\mathrm{a}, \mathrm{b}}$ \\
\hline Birth weight (g) & $1,173 \pm 214$ & $1,705 \pm 178$ & $1,276 \pm 178$ & $<0.001^{a, b, c}$ \\
\hline PROM & $115(23.2)$ & $56(27.1)$ & $12(4.1)$ & $<0.001^{\mathrm{b}, \mathrm{c}}$ \\
\hline Born via cesarean section & $194(39.2)$ & $52(25.1)$ & $223(75.3)$ & $<0.001^{\mathrm{a}, \mathrm{b}, \mathrm{c}}$ \\
\hline Days of ventilation (d) & $7.5 \pm 11.0$ & $3.2 \pm 5.1$ & $1.4 \pm 7.5$ & $<0.001^{\mathrm{a}, \mathrm{b}, \mathrm{c}}$ \\
\hline IRDS & $254(51.3)$ & $99(47.8)$ & $36(12.2)$ & $<0.001^{\mathrm{b}, \mathrm{c}}$ \\
\hline Sepsis & $196(39.8)$ & $60(29.0)$ & $77(26.0)$ & $<0.001^{\mathrm{a}, \mathrm{c}}$ \\
\hline IVH & $129(26.1)$ & $28(13.5)$ & $18(6.1)$ & $<0.001^{\mathrm{a}, \mathrm{b}, \mathrm{c}}$ \\
\hline Maternal height $(\mathrm{cm})$ & $166 \pm 6.1$ & $167 \pm 6.5$ & $166 \pm 7.0$ & 0.306 \\
\hline Pre-existent hypertension & $16(3.2)$ & $3(1.5)$ & $25(8.6)$ & $<0.001^{\mathrm{b}, \mathrm{c}}$ \\
\hline Hypertension during pregnancy & $104(21.0)$ & $11(5.3)$ & $152(51.4)$ & $<0.001^{\mathrm{a}, \mathrm{b}, \mathrm{c}}$ \\
\hline Smoking during pregnancy & $145(29.3)$ & $55(26.6)$ & $112(37.8)$ & $0.023^{\mathrm{b}, \mathrm{c}}$ \\
\hline Caucasian maternal ethnicity & $417(84.4)$ & $177(87.2)$ & $252(85.7)$ & 0.628 \\
\hline Married (parents) & $438(88.8)$ & $192(92.8)$ & $249(84.1)$ & 0.114 \\
\hline Low parental SES & $214(45.1)$ & 75 (37.9) & $123(42.4)$ & 0.228 \\
\hline
\end{tabular}

IRDS, infants respiratory distress syndrome; IVH, intraventricular hemorrhage; NEC, necrotizing enterocolitis; PROM, premature rupture of membranes; SGA, small-for-gestationalage; VLBW, very low birth weight; $V P$, very preterm

a $P$ value $<0.05$ for $\mathrm{VP}+\mathrm{NLBW}+\mathrm{vs}$. VP+NLBW-

${ }^{b} P$ value $<0.05$ for $V P+V L B W-V S$. VP $-N L B W+$

${ }^{c} P$ value $<0.05$ for $V P+N L B W+$ vs. $V P-N L B W+$.

${ }^{\mathrm{d} G i r l s:}$ target height $=[($ height of father in $\mathrm{cm}+$ height of mother in $\mathrm{cm}-13) / 2]+4.5$; boys: target height $=[($ height of father in $\mathrm{cm}+$ height of mother in $\mathrm{cm}+13) / 2]+4.5$.

Values represent mean \pm SD or $n(\%)$. Continuous variables were compared with the one-way ANOVA test when comparing the three groups, and the independent $t$-test when comparing two groups. Dichotomous variables were compared with the $x^{2}$-test.

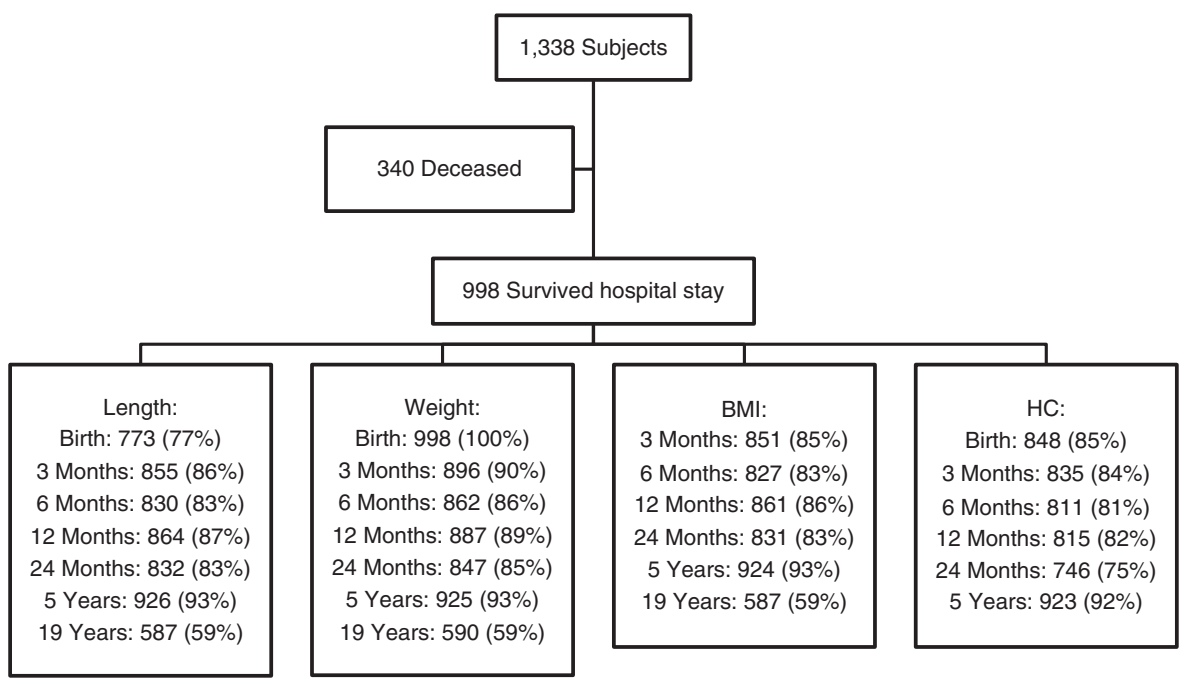

Figure 2. Follow-up response for the different growth parameters at all follow-up visits. 
Table 2. Perinatal characteristics of the responders vs. non-responders at age 19 years

\begin{tabular}{|c|c|c|c|}
\hline & $\begin{array}{c}\text { Responders at } \\
\text { age } 19 \text { years, } \\
n=590\end{array}$ & $\begin{array}{c}\text { Non-responders } \\
\text { at age } 19 \text { years, } \\
\quad n=408\end{array}$ & $P$ value \\
\hline Male & $265(44.9)$ & $258(63.2)$ & $<0.001$ \\
\hline Birth weight (g) & $1,301 \pm 299$ & $1,331 \pm 261$ & 0.095 \\
\hline $\begin{array}{l}\text { Gestational age } \\
\text { (weeks) }\end{array}$ & $31.0 \pm 2.5$ & $31.2 \pm 2.6$ & 0.265 \\
\hline PROM & $105(17.8)$ & $78(19.1)$ & 0.596 \\
\hline $\begin{array}{l}\text { Born via cesarean } \\
\text { section }\end{array}$ & $289(49.0)$ & $180(44.1)$ & 0.130 \\
\hline $\begin{array}{l}\text { Apgar score }>7 \text { after } \\
5 \mathrm{~min}\end{array}$ & $492(83.4)$ & $331(81.1)$ & 0.618 \\
\hline $\begin{array}{l}\text { Duration of hospital } \\
\text { stay (d) }\end{array}$ & $67.3 \pm 30.3$ & $69.9 \pm 35.4$ & 0.464 \\
\hline $\begin{array}{l}\text { Days of } \\
\text { ventilation (d) }\end{array}$ & $4.8 \pm 9.5$ & $4.7 \pm 9.4$ & 0.840 \\
\hline IRDS & $232(39.3)$ & $157(38.5)$ & 0.789 \\
\hline Sepsis & $193(32.8)$ & $140(34.4)$ & 0.592 \\
\hline IVH & $95(16.1)$ & 80 (19.6) & 0.152 \\
\hline NEC & $36(6.1)$ & $21(5.1)$ & 0.523 \\
\hline SGA status & $170(28.8)$ & $115(28.3)$ & 0.848 \\
\hline Target height (SD) ${ }^{\mathrm{a}}$ & $0.0 \pm 0.8$ & $-0.2 \pm 0.9$ & 0.001 \\
\hline Maternal height $(\mathrm{cm})$ & $167 \pm 6.3$ & $165 \pm 6.6)$ & 0.006 \\
\hline $\begin{array}{l}\text { Pre-existent } \\
\text { hypertension }\end{array}$ & $33(5.6)$ & $11(2.7)$ & 0.030 \\
\hline $\begin{array}{l}\text { Hypertension during } \\
\text { pregnancy }\end{array}$ & $168(28.5)$ & $99(24.3)$ & 0.140 \\
\hline $\begin{array}{l}\text { Smoking during } \\
\text { pregnancy }\end{array}$ & $178(30.2)$ & $134(32.8)$ & 0.644 \\
\hline $\begin{array}{l}\text { Caucasian maternal } \\
\text { ethnicity }\end{array}$ & $519(88.9)$ & $327(80.3)$ & $<0.001$ \\
\hline Married (parents) & $529(89.7)$ & $350(86.2)$ & 0.324 \\
\hline Low parental SES & $208(35.5)$ & $204(54.1)$ & $<0.001$ \\
\hline \multicolumn{4}{|l|}{ VPNLBW status } \\
\hline $\mathrm{VP}+/ \mathrm{VLBW}+$ & $302(51.2)$ & $193(47.3)$ & 0.392 \\
\hline $\mathrm{VP}+/ \mathrm{VLBW}-$ & $115(19.5)$ & $92(22.5)$ & \\
\hline VP - NLBW+ & $173(29.3)$ & $123(30.1)$ & \\
\hline
\end{tabular}

IRDS, infants respiratory distress syndrome; IVH, intraventricular hemorrhage; NEC, necrotizing enterocolitis; PROM, premature rupture of membranes; SGA, small-forgestational-age; VLBW, very low birth weight; $V P$, very preterm.

${ }^{*} P$ value $<0.05$ for $V P+N L B W+$ vs. VP+NLBW -

${ }^{+} P$ value $<0.05$ for $V P+N L B W+V s$. VP $-N L B W+$

${ }^{\ddagger} p$ value $<0.05$ for $\mathrm{VP}+\mathrm{VLBW}-\mathrm{vs}$. VP $-\mathrm{NLBW}+$

${ }^{\mathrm{a}}$ Girls: target height $=[($ height of father in $\mathrm{cm}+$ height of mother in $\mathrm{cm}-13) / 2]+4.5$; boys: target height $=[($ height of father in $\mathrm{cm}+$ height of mother in $\mathrm{cm}+13) / 2]+4.5$. Values represent mean $\pm \mathrm{SD}$ or $n(\%)$. Continuous variables were compared with the one-way ANOVA test when comparing the three groups, and the independent $t$ test when comparing two groups. Dichotomous variables were compared with the $x^{2}$ - test.

between ages 5 and 19. Between birth and age 5, HC SDS increased significantly in the VP-/VLBW+ group, whereas there was no change in SDS in the VP+/VLBW+ and $\mathrm{VP}+/ \mathrm{VLBW}$ - groups. The greatest SDS change took place between birth and 3 months.

\section{DISCUSSION}

In this study, we found significantly different growth patterns for length/height, weight, BMI, and HC between VP+/VLBW+, $\mathrm{VP}+/ \mathrm{VLBW}-$, and $\mathrm{VP}-/ \mathrm{VLBW}+$ infants. This indicates that the terms VP and VLBW describe two different entities, which impact differently on growth.

We observed that VP-/VLBW+ infants were severely growth-restricted at birth, as evidenced by an SGA rate of $79.4 \%$, and exhibited rapid catch-up growth postnatally. However, they remained shorter and lighter, and with a smaller $\mathrm{HC}$, as compared with the other two groups. In contrast, the VP +/VLBW+ and VP+/VLBW - groups showed sharp decreases in length/height SDS and weight SDS between birth and 3 months, which could most likely be attributed to the greater percentage of children with neonatal illnesses or to inadequate nutritional support for their degree of illness, although this was not measured in our study (19). In a recent systematic review, poor early postnatal growth after preterm birth was associated with adverse neurodevelopment (20). Conversely, yet another study found that rapid early postnatal growth in subjects born SGA was associated with cardiometabolic disease propensity (21). HC SDS did not change for both groups. Nevertheless, despite this parallelism in growth patterns, the VP+/VLBW+ group remained below the means of the norm population for length/height, weight, and HC. In contrast, the length/height, weight, and $\mathrm{HC}$ of the VP+/VLBW - group remained close to the population reference mean.

At age 19 years, all three groups had a BMI that was comparable to the norm population, with significant increases in BMI SDS for the VP+/VLBW+ and VP - /VLBW+ groups between ages 5 and 19. This pattern has previously been associated with an increased risk of coronary events later in life (22).

A previous study found significantly different early neonatal outcomes between VP and VLBW infants (13). This was replicated in our study, in which we observed a greater percentage of neonatal morbidities in the VP+/VLBW+ and VP +/VLBW - groups. VP - /VLBW + infants, in turn, were more often born SGA. In addition, they were more often born to mothers who had (pre-existent) hypertension or who smoked during pregnancy, which are known risk factors for IUGR (23). This suggests that short-term outcomes are significantly different depending on the classification that is used. Our current findings indicate that the differences between these groups could be extended with growth up until adulthood, with the VP - /VLBW+ group, and to a lesser extent the VP+/VLBW + group, showing a growth pattern that has previously been associated with cardiometabolic disease (21).

Because of the different neonatal outcomes and growth patterns found in our study between children born VP and/or with a VLBW, we argue that these terms cannot be used interchangeably. Therefore, findings from studies in children born with VLBW cannot be automatically extrapolated to children born VP, and vice versa.

For future studies on preterm infants, we suggest that researchers strive to use the same inclusion criteria, enabling 

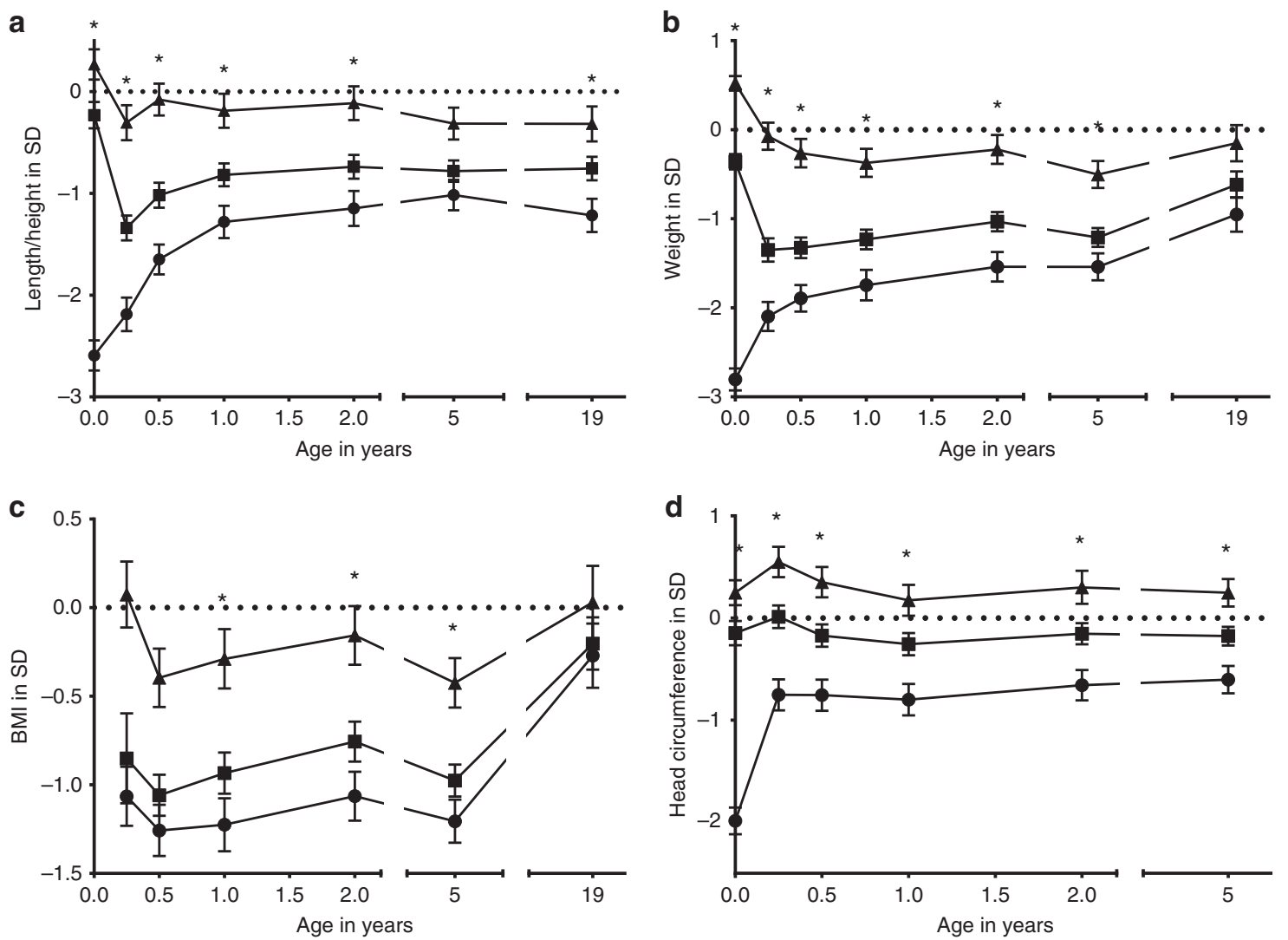

Figure 3. Growth for length/height (a), weight (b), BMI (c), and head circumference (d), expressed as SD scores, for all three groups. Squares =VP $+/ \mathrm{VLBW}+$, triangles $=\mathrm{VP}+/ \mathrm{VLBW}-$, and circles $=\mathrm{VP}-\mathrm{NLBW}+$; the error bars represent $95 \% \mathrm{Cls}$. ${ }^{*} P$ value $<0.05$ between all three groups, analyzed per measurement point.

comparisons between different cohorts. Notably, it is desirable to use inclusion criteria that result in representative samples of preterm infants. The definition of prematurity is based on pregnancy duration and not on birth weight, and with current technologies, pregnancy dating can be determined very accurately, especially in the first trimester $(24,25)$. Therefore, we would strongly recommend that, at least for industrialized countries, the inclusion of preterm subjects is based on gestational age rather than on birth weight.

Our study has several strengths and limitations. The major strengths of our study are its large sample size, long-term follow-up, and completeness of data, including growth parameters.

Our study also has some limitations. First, the follow-up rate between ages 5 and 19 dropped substantially. A nonresponse analysis (Table 2) showed that non-response was associated with male gender, non-Caucasian ethnicity, and a lower SES. However, aside from gender, these factors were not significantly different between the three study groups. Moreover, responders had a 0.2 SD higher target height SDS, and their mothers were more often hypertensive compared with non-responders. However, perinatal characteristics, including SGA status, did not differ between response groups. Moreover, the distribution of subjects among the three study groups was not different between responders and nonresponders. Therefore, although small differences were present, we think that our results at age 19 are not subject to attrition bias. Second, subjects in this cohort were born in 1983. Therefore, our data are not representative for the current generation of preterm infants (26), as neonatal care has advanced significantly in the past three decades. However, preterm infants still show EUGR despite improved neonatal care (27), and VP and/or VLBW subjects can therefore still be expected to have different growth patterns. Nevertheless, these growth patterns will presumably be more favorable than the growth patterns observed in this study. As IUGR pregnancies are nowadays strictly monitored and labor is induced if necessary (23), infants will be less likely severely growth-restricted at birth, leading to lower numbers being VLBW but not VP. Moreover, because of improved nutritional strategies, which include earlier introduction and rapid increases in protein intake $(28,29)$, as well as an increased awareness of the benefits of human breast milk (30), VP +/VLBW+ and VP+/VLBW - infants will likely show a smaller decrease in SDS, whereas VP - /VLBW+ infants will show improved catch-up growth. Third, although postnatal growth charts have been designed specifically for preterm infants, we did not use these reference data, as they apply to 
Table 3. Changes in SD scores within the groups for length/height, weight, BMI, and HC over time

\begin{tabular}{|c|c|c|c|c|c|c|}
\hline & \multicolumn{2}{|c|}{$\mathrm{VP}+/ \mathrm{VLBW}+$} & \multicolumn{2}{|c|}{$\mathrm{VP}+\mathrm{NLBW}-$} & \multicolumn{2}{|c|}{ VP - /VLBW+ } \\
\hline & $\beta(95 \% \mathrm{Cl})$ & $P$ value & $\beta(95 \% \mathrm{Cl})$ & $P$ value & $\beta(95 \% \mathrm{Cl})$ & $P$ value \\
\hline \multicolumn{7}{|l|}{ Length/height } \\
\hline Birth-3 months & $-1.1(-1.3$ to -1.0$)$ & $<0.001$ & $-0.6(-0.8$ to -0.4$)$ & $<0.001$ & 0.4 (0.2 to 0.6$)$ & $<0.001$ \\
\hline 3 months -1 year & 0.5 (0.4 to 0.6$)$ & $<0.001$ & 0.1 (-0.1 to 0.3$)$ & 0.20 & 0.9 (0.8 to 1.0$)$ & $<0.001$ \\
\hline \multicolumn{7}{|l|}{ Weight } \\
\hline Birth-19 years & $-0.3(-0.4$ to -0.1$)$ & 0.001 & $-0.7(-0.9$ to -0.5$)$ & $<0.001$ & 1.9 (1.6 to 2.1$)$ & $<0.001$ \\
\hline Birth-3 months & $-1.0(-1.1$ to -0.9$)$ & $<0.001$ & $-0.6(-0.7$ to -0.4$)$ & $<0.001$ & 0.7 (0.5 to 0.9$)$ & $<0.001$ \\
\hline \multicolumn{7}{|l|}{$B M I$} \\
\hline 3 months -19 years & 0.6 (0.3 to 1.0$)$ & $<0.001$ & $0.0(-0.3$ to 0.2$)$ & 0.72 & 0.8 (0.6 to 1.0$)$ & $<0.001$ \\
\hline 3 months -1 year & $-0.1(-0.3$ to 0.2$)$ & 0.52 & $-0.4(-0.6$ to -0.2$)$ & $<0.001$ & $-0.2(-0.3$ to 0.0$)$ & 0.06 \\
\hline 1 year -5 years & 0.0 (-0.1 to 0.1$)$ & 0.43 & $-0.1(-0.3$ to 0.0$)$ & 0.10 & 0.0 (-0.1 to 0.2$)$ & 0.78 \\
\hline 5 years -19 years & 0.8 (0.6 to 0.9 ) & $<0.001$ & 0.5 (0.3 to 0.7$)$ & $<0.001$ & 0.9 (0.8 to 1.1$)$ & $<0.001$ \\
\hline \multicolumn{7}{|l|}{$H C$} \\
\hline Birth-5 years & $0.0(-0.2$ to 0.1$)$ & 0.66 & $0.0(-0.2$ to 0.2$)$ & 0.99 & $1.4(1.2$ to 1.5$)$ & $<0.001$ \\
\hline
\end{tabular}

$\mathrm{BMI}$,body mass index; $\mathrm{HC}$, head circumference; VLBW, very low birth weight; VP, very preterm.

Values represent $\beta(95 \% \mathrm{Cl})$, as compared with the generalized estimating equation.

the current generation of NICU-treated infants. Instead, we have used reference charts that are applicable to Dutch children born in the 1980s (refs 15,17). Although these charts were not designed specifically for preterm infants, they do allow comparison between the study groups. Finally, the observed growth patterns, especially those of the VP-/VLBW+ group, could also be partly ascribed to regression to the mean. However, this phenomenon is difficult to quantify and to separate from catch-up growth. Nonetheless, despite possible regression to the mean, the three groups still show significantly different growth at age 19 .

In conclusion, infants born $\mathrm{VP}+/ \mathrm{VLBW}+, \mathrm{VP}+/ \mathrm{VLBW}-$, or $\mathrm{VP}-/ \mathrm{VLBW}+$ appear to have significantly different growth patterns, and, therefore, the terms VP and VLBW cannot be used interchangeably. Because pregnancy dating can be reliably assessed nowadays, we recommend, at least for industrialized countries, to use gestational age instead of birth weight as the inclusion criterion for future studies in preterm infants.

\section{DUTCH POPS-19 COLLABORATIVE STUDY GROUP}

E.T.M. Hille ${ }^{3}$, C.H. de Groot ${ }^{3}$, H. Kloosterboer-Boerrigter ${ }^{3}$, A.L. den Ouden ${ }^{3}$, A. Rijpstra ${ }^{3}$, S.P. Verloove-Vanhorick ${ }^{3}$, J.A. Vogelaar ${ }^{3}$, J.H. Kok, ${ }^{4}$ A. Ilsen ${ }^{4}$, M. van der Lans ${ }^{4}$, W.J.C. Boelen-van der Loo ${ }^{4}$, T. Lundqvist ${ }^{4}$, H.S.A. Heymans ${ }^{4}$, E.J. Duiverman ${ }^{5}$, W.B. Geven ${ }^{5}$, M.L. Duiverman ${ }^{5}$, L.I. Geven ${ }^{5}$, E.J.L.E. Vrijlandt ${ }^{5}$, A.L.M. Mulder ${ }^{6}$, A. Gerver ${ }^{6}$, L.A.A. Kollée ${ }^{7}$, L. Reijmers ${ }^{7}$, R. Sonnemans ${ }^{7}$, J.M. Wit ${ }^{8}$, F.W. Dekker ${ }^{8}$, M.J.J. Finken ${ }^{8}$, N. Weisglas-Kuperus ${ }^{9}$, M.G. KeijzerVeen ${ }^{9}$, A.J. van der Heijden ${ }^{9}$, J.B. van Goudoever ${ }^{9}$, M.M. van Weissenbruch ${ }^{10}$, A. Cranendonk ${ }^{10}$, H.A. Delemarre-van de Waal ${ }^{10}$, L. de Groot ${ }^{10}$, J.F. Samsom ${ }^{10}$, L.S. de Vries ${ }^{11}$, K.J. Rademaker ${ }^{11}$, E. Moerman ${ }^{11}$, M. Voogsgeerd ${ }^{11}$, M.J.K. de Kleine $^{12}$, P. Andriessen ${ }^{12}$, C.C.M. Dielissen-van Helvoirt ${ }^{12}$, I. Mohamed ${ }^{12}$, H.L.M. van Straaten ${ }^{13}$, W. Baerts ${ }^{13}$, G.W. Veneklaas Slots-Kloosterboer ${ }^{13}$, E.M.J. Tuller-Pikkemaat ${ }^{13}$, M.H. Ens-Dokkum ${ }^{14}$, G.J. van Steenbrugge ${ }^{15}$

${ }^{3}$ TNO Quality of Life, Leiden; ${ }^{4} E m m a$ Children's Hospital AMC, Amsterdam; ${ }^{5}$ University Hospital Groningen, Beatrix Children's Hospital, Groningen; ${ }^{6}$ University Hospital Maastricht, Maastricht; ${ }^{7}$ University Medical Center St Radboud, Nijmegen; ${ }^{8}$ Leiden University Medical Center, Leiden; ${ }^{9}$ Erasmus MC-Sophia Children's Hospital, University Medical Center Rotterdam; ${ }^{10}$ V.U. University Medical Center, Amsterdam; ${ }^{11}$ Wilhelmina Children's Hospital, UMC, Utrecht; ${ }^{12}$ Máxima Medical Center, Veldhoven; ${ }^{13}$ Isala Clinics, Zwolle; ${ }^{14}$ Royal Effatha Guyot Group, Zoetermeer; ${ }^{15}$ Association for Parents of Premature Babies.

Disclosure: The authors declare no conflict of interest. 


\section{REFERENCES}

1. Wit JM, Finken MJ, Rijken M, de Zegher F. Preterm growth restraint: a paradigm that unifies intrauterine growth retardation and preterm extrauterine growth retardation and has implications for the small-forgestational-age indication in growth hormone therapy. Pediatrics 2006;117:e793-5.

2. Euser AM, de Wit CC, Finken MJ, Rijken M, Wit JM. Growth of preterm born children. Horm Res 2008;70:319-28.

3. Casey PH, Whiteside-Mansell L, Barrett K, Bradley RH, Gargus R. Impact of prenatal and/or postnatal growth problems in low birth weight preterm infants on school-age outcomes: an 8-year longitudinal evaluation. Pediatrics 2006;118:1078-86.

4. Cooke RW, Foulder-Hughes L. Growth impairment in the very preterm and cognitive and motor performance at 7 years. Arch Dis Child 2003;88: 482-7.

5. Euser AM, Finken MJ, Keijzer-Veen MG, Hille ET, Wit JM, Dekker FW. Associations between prenatal and infancy weight gain and BMI, fat mass, and fat distribution in young adulthood: a prospective cohort study in males and females born very preterm. Am J Clin Nutr 2005;81:480-7.

6. Doyle LW, Faber B, Callanan C, Ford GW, Davis NM. Extremely low birth weight and body size in early adulthood. Arch Dis Child 2004;89: 347-50.

7. Ford GW, Doyle LW, Davis NM, Callanan C. Very low birth weight and growth into adolescence. Arch Pediatr Adolesc Med 2000;154:778-84.

8. Hack M, Schluchter M, Cartar L, Rahman M, Cuttler L, Borawski E. Growth of very low birth weight infants to age 20 years. Pediatrics 2003;112:e30-8.

9. Latal-Hajnal B, von SK, Kovari H, Bucher HU, Largo RH. Postnatal growth in VLBW infants: significant association with neurodevelopmental outcome. J Pediatr 2003;143:163-70.

10. Lucas A, Morley R, Cole TJ, et al. Early diet in preterm babies and developmental status at 18 months. Lancet 1990;335:1477-81.

11. Saigal S, Stoskopf B, Streiner D, Paneth N, Pinelli J, Boyle M. Growth trajectories of extremely low birth weight infants from birth to young adulthood: a longitudinal, population-based study. Pediatr Res 2006;60: 751-8.

12. Campbell S. The prediction of fetal maturity by ultrasonic measurement of the biparietal diameter. J Obstet Gynaecol Br Commonw 1969;76:603-9.

13. Lapeyre D, Klosowski S, Liska A, Zaoui C, Gremillet C, Truffert P. Very preterm infant $(<32$ weeks) vs very low birth weight newborns (1500 grammes): comparison of two cohorts. Arch Pediatr 2004;11:412-6.

14. Brandt I, Sticker EJ, Gausche R, Lentze MJ. Catch-up growth of supine length/height of very low birth weight, small for gestational age preterm infants to adulthood. J Pediatr 2005;147:662-8.

15. Niklasson A, Ericson A, Fryer JG, Karlberg J, Lawrence C, Karlberg P. An update of the Swedish reference standards for weight, length and head circumference at birth for given gestational age (1977-1981). Acta Paediatr Scand 1991;80:756-62.

16. Fredriks AM, van BS, Burgmeijer RJ, et al. Continuing positive secular growth change in The Netherlands 1955-1997. Pediatr Res 2000;47:316-23.

17. Fredriks AM, van BS, Wit JM, Verloove-Vanhorick SP. Body index measurements in 1996-7 compared with 1980. Arch Dis Child 2000;82: 107-2.

18. Figueiras A, Domenech-Massons JM, Cadarso C. Regression models: calculating the confidence interval of effects in the presence of interactions. Stat Med 1998;17:2099-105.

19. Embleton NE, Pang N, Cooke RJ. Postnatal malnutrition and growth retardation: an inevitable consequence of current recommendations in preterm infants? Pediatrics 2001;107:270-3

20. Ong KK, Kennedy K, Castaneda-Gutierrez E, et al. Postnatal growth in preterm infants and later health outcomes: a systematic review. Acta Paediatr 2015;104:974-86.

21. Leunissen RW, Kerkhof GF, Stijnen T, Hokken-Koelega A. Timing and tempo of first-year rapid growth in relation to cardiovascular and metabolic risk profile in early adulthood. JAMA 2009;301:2234-42.

22. Barker DJ, Osmond C, Forsen TJ, Kajantie E, Eriksson JG. Trajectories of growth among children who have coronary events as adults. N Engl J Med 2005;353:1802-9.

23. American College of O, Gynecologists. ACOG practice bulletin no. 134: fetal growth restriction. Obstet Gynecol 2013;121:1122-33.

24. Mongelli M, Wilcox M, Gardosi J. Estimating the date of confinement: ultrasonographic biometry versus certain menstrual dates. Am J Obstet Gynecol 1996;174:278-81.

25. Neilson JP. Ultrasound for fetal assessment in early pregnancy. Cochrane Database Syst Rev 2000: CD000182.

26. Stoelhorst GM, Rijken M, Martens SE, et al. Changes in neonatology: comparison of two cohorts of very preterm infants (gestational age $<32$ weeks): the Project On Preterm and Small for Gestational Age Infants 1983 and the Leiden Follow-Up Project on Prematurity 19961997. Pediatrics 2005;115:396-405.

27. Ehrenkranz RA, Younes N, Lemons JA, et al. Longitudinal growth of hospitalized very low birth weight infants. Pediatrics 1999;104:280-9.

28. Kashyap S, Schulze KF, Forsyth M, Dell RB, Ramakrishnan R, Heird WC. Growth, nutrient retention, and metabolic response of low-birth-weight infants fed supplemented and unsupplemented preterm human milk. Am J Clin Nutr 1990;52:254-62.

29. Miller J, Makrides M, Gibson RA, et al. Effect of increasing protein content of human milk fortifier on growth in preterm infants born at $<31$ wk gestation: a randomized controlled trial. Am J Clin Nutr 2012;95: $648-55$.

30. Underwood MA. Human milk for the premature infant. Pediatr Clin North Am 2013;60:189-207. 